\title{
Measurement report: Hygroscopic growth of ambient fine particles measured at five sites of China
}

Lu Chen ${ }^{1}$, Fang Zhang ${ }^{2}$, Dongmei Zhang ${ }^{1}$, Xinming Wang ${ }^{3}$, Wei Song ${ }^{3}$, Jieyao Liu ${ }^{1}$, Jingye Ren ${ }^{1}$, Sihui Jiang ${ }^{1}$, Xue $\mathrm{Li}^{1}$ and Zhanqing $\mathrm{Li}^{4 *}$

$5 \quad{ }^{1}$ College of Global Change and Earth System Science, Beijing Normal University, Beijing 100875, China

${ }^{2}$ Environmental Science and Engineering Research Center, School of Civil and Environmental Engineering, Harbin Institute of Technology (Shenzhen), 518055 Shenzhen, China

${ }^{3}$ State Key Laboratory of Organic Geochemistry, Guangzhou Institute of Geochemistry, Chinese

${ }^{4}$ Earth System Science Interdisciplinary Center and Department of Atmospheric and Oceanic Science, University of

10 Maryland, College Park, MD, USA

Correspondence to: F. Zhang (fang.zhang@bnu.edu.cn) and Z.Li (zli@atmos.umd.edu)

Abstract. The aerosol hygroscopic growth describes the interaction between aerosols and water vapor, which varies largely depending on the chemical composition, types and emissions of gas precursors under diverse environments. In this study, we analysed size-resolved hygroscopic growth measured at

15 five field sites of China by a Hygroscopic Tandem Differential Mobility Analyzer (H-TDMA). Results show that the probability density function of hygroscopic growth factor (GF-PDF) at the megacity sites of Guangzhou (GZ), Shanghai (SH) and Beijing (BJ) was generally with bimodal hydrophobic and hydrophilic modes; while a unimodal hydrophilic mode was dominated at the suburb sites of Xinzhou (XZ) and Xingtai (XT) throughout the measured particle size of 40-200 $\mathrm{nm}$. As a result, the more

20 hygroscopic $(\mathrm{MH})$ mode accounts for a number fraction of $>80 \%$ at the suburb sites, compared to only $20-40 \%$ at the megacity sites. Further analysis shows that the GF value increases with the aggravated $\mathrm{PM}_{2.5}$ pollution at the sites (BJ, XZ and $\mathrm{XT}$ ) of north China, but that is not the case for GZ and $\mathrm{SH}$ which are located in the southern regions. The distinct dependence of GF on the variations of $\mathrm{PM}_{2.5}$ concentrations among the sites suggests the spatial variability in particle composition with the evolution

25 of pollution events in different regions of China. Moreover, different particle hygroscopic behaviors during new particle formation (NPF) events were observed at the five sites, reflecting the distinct mechanisms of NPF in diverse atmospheric environments. By including results from more sites, we find that the aerosol particles observed at those suburb sites are basically more hygroscopic than those in megacities. However, a large variability in the hygroscopic parameter $\kappa$ at a given particle size among 
30 different sites is also observed, suggesting a complex impact from local sources and atmospheric processes. The measured dataset is helpful to improve understanding of the formation of fine particles and the regional environmental and climate change.

\section{Introduction}

Aerosol hygroscopicity is characterized by the aerosol water uptake capacity when the environmental relative humidity (RH) increases (Swietlicki et al., 1999). The particle volume increases after hygroscopic growth, which leads to increased extinction and scattering, and then accelerates the reduction of atmospheric visibility (Kreidenweis and Asa-Awuku, 2013; Tang and Munkelwitz, 1994). On the other hand, when particles are in the same ambient RH conditions, those with strong hygroscopic ability tend to produce more cloud particles, increasing the cloud lifetime and decreasing

40 the precipitation (Kandler and Schütz, 2007; Krüger et al., 2013; Wu et al., 2013). In addition, the aerosol particles after hygroscopic growth have distinct sedimentation position and sedimentation rate in the respiratory system compared to the dry particles, thereby inducing different health effects (Peters et al., 1997; Broday and Georgopoulos, 2001). Therefore, aerosol hygroscopicity is one of the important physicochemical properties of aerosol particles (Gasparini et al., 2004) and plays a critical role in air quality, climate and human health. The in-depth understanding of the hygroscopic behavior of atmospheric aerosols is of great significance in many research fields.

In order to measure the aerosol hygroscopicity, a variety of instruments and techniques have been developed and employed, such as Hygroscopic Tandem Differential Mobility Analyzer (H-TDMA), Cloud Condensation Nuclei Counter (CCNC), and humidified nephelometer. Among them, CCNC

50 gives an estimate of aerosol hygroscopicity under different supersaturations, but cannot provide information of particle mixing state (Roberts \& Nenes, 2005). Nephelometer measures the humiditydependent scattering coefficient over the whole size range (Y. Kuang et al., 2018), but cannot directly obtain the size-resolved particle hygroscopicity. While H-TDMA can not only measure the hygroscopic growth factor (GF) of size-resolved aerosols under different RHs, but also deduce the mixing state of 55 the particles (McMurry et al., 1996; Weingartner et al., 2002). In addition, H-TDMA measurement is 
based on particle number concentration, which has unique advantages in investigating the characteristics of ultrafine-mode particles, thus has been widely used.

To date, a number of short-term field measurements of aerosol hygroscopic growth using the $\mathrm{H}-$ TDMA system have been successively carried out in the North China Plain (NCP) (Massling et al., 60 2007, 2009; Liu et al., 2011; Wu et al., 2013, 2015, 2016; Wang et al., 2017; Zhang et al., 2017; Fan et al., 2020), the Yangtze River Delta (YRD) (Zhang et al., 2011; Ye et al., 2013; Xie et al., 2017), and the Pearl River Delta (PRD) (Cheng et al., 2008; Tan et al., 2013, 2017). However, most of the studies are limited to one single site or one region. A comprehensive comparison of the aerosol hygroscopic growth behavior from multiple sites has been lacking. Based on the data of a single site, for example, it is difficult to obtain insights of how particle hygroscopicity affects air pollution, and thereby unable to accurately parameterize the relationship between the two on a larger spatial scale in models. In reality, distinct dependence of aerosol hygroscopicity on air pollution levels was found by Meier et al. (2009) and Massling et al. (2009). In addition, the particle hygroscopic growth is highly correlated with the ambient RH, particle size, chemical composition and aerosol mixing state (Pitchford and McMurry, 70 1994; Tan et al., 2013; Li et al., 2016; Zhang et al., 2017, 2019), which is strongly impacted by meteorological variations, aerosol formation mechanism and atmospheric processes (Liu et al., 2011; Wang et al., 2017), thus varying widely among the observations in diverse environments. For example, several observations in urban atmosphere showed that an enhanced aerosol hygroscopicity and CCN activation correlate with the new particle formation (NPF) events (Lance et al., 2013; Wu et al., 2015; 75 Liu et al, 2021), while it was observed decreased at a mid-level mountain range (Wu et al., 2013), at an urban site (Wang et al., 2018), and in forest region (Deng et al., 2018). Moreover, it has been found the size dependence of aerosol hygroscopicity was quite different among different atmospheric environment conditions (Zhang et al., 2014, 2017; Fan et al., 2020; Tan et al., 2013; Jiang et al., 2016; Cai et al., 2017, 2018).

Therefore, an extensive and comprehensive study of spatial variations of aerosol hygroscopicity is necessary to better understand the aerosol hygroscopic behavior under different pollution conditions, and the effect of atmospheric processes (e.g. pollution evolution, NPF events) on aerosol hygroscopicity in diverse environment also needed to be fully elucidated. Aerosol hygroscopic growth is investigated 
here at five sites in China using measurements made with the H-TDMA system. The overall different hygroscopic modes, and the diurnal cycle among the five sites. To understand the effects of atmospheric processes on particle hygroscopicity and mixing state, the dependence of the particles hygroscopicity on the pollution evolution is explored. The particle hygroscopic behavior during NPF and non-NPF events at the five sites is also compared.

\section{Sites and Measurements}

\subsection{Sampling sites}

The field campaigns, which were designed with the scientific aim of a comprehensive study of the physiochemical properties of ambient aerosols, have been conducted at five sites in China, part of which are reviewed in $\mathrm{Li}$ et al. (2019). The five sites including three megacity sites, Beijing (BJ: $40.05^{\circ} \mathrm{N}$, $\left.116.09^{\circ} \mathrm{E}\right)$, Shanghai $\left(\mathrm{SH}: 31.40^{\circ} \mathrm{N}, 121.45^{\circ} \mathrm{E}\right)$, Guangzhou (GZ: $\left.23.01^{\circ} \mathrm{N}, 113.33^{\circ} \mathrm{E}\right)$, and two suburb sites, Xinzhou (XZ: $\left.38.24^{\circ} \mathrm{N}, 112.43^{\circ} \mathrm{E}\right)$ and Xingtai (XT: $\left.37.18^{\circ} \mathrm{N}, 114.37^{\circ} \mathrm{E}\right)$ (Fig. 1). The Beijing site is between the third and fourth Ring Road in the north of Beijing, located at the meteorological tower branch of the Institute of Atmospheric Physics (IAP), Chinese Academy of Sciences, which is usually affected by local traffic and cooking emissions (Sun et al., 2015). The observation periods were from 25 May to 18 June of 2017. The Shanghai site was located in the Baoshan Meteorological Bureau of Shanghai, which is near the main road (Youyi Road) with heavy traffic. So, it is mainly influenced by local emission sources from traffic and business activities that can be viewed as an urban site. The observation periods at Shanghai site were from 6 April to 6 May 2020. The filed campaign at Guangzhou site was conducted at the meteorological observation station of the Guangzhou City Meteorological Bureau. The site is with an altitude of $145 \mathrm{~m}$, and is about $120 \mathrm{~m}$ above the city average elevation of the PRD (Tan et al., 2017), surrounded by a few light industrial plants and residential areas. In particular, at night, it could be affected by the cooking emissions from a nearby night market. The observation took place in November 2019. The Xinzhou air and ground observation campaign was conducted in the suburb of Xinzhou City, Shanxi Province, which is located between the Luliang and 
110 Taihang Mountains dominated by farmland without obvious emission sources nearby. Due to its high altitude, the aerosols in this area are mainly transmitted from elsewhere and are thus aged (Zhang et al., 2017). Aerosol hygroscopic growth was investigated at this site from 28 June to 22 July 2020. The experiment in Xingtai was conducted at the National Meteorological Basic Station from 1 May to 15 June 2016. This sampling site is located about $17 \mathrm{~km}$ northwest of the Xingtai city, the central part of the NCP with many heavy industrial factories nearby such as power plants and steelworks (Wang et al., 2018b).

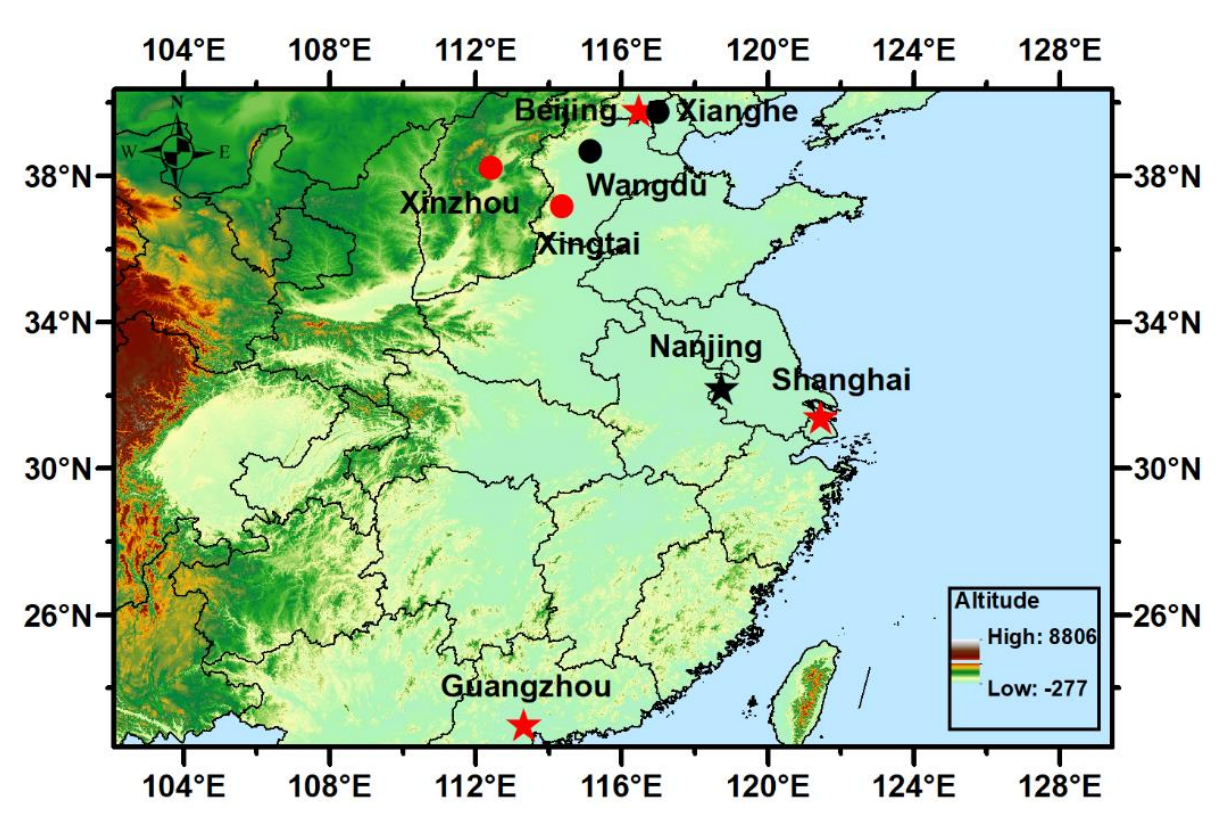

Figure 1. The map location of the sampling sites in this study (in red) and in previous studies (in black). The pentacles represent megacity sites and circles represent suburb sites. This map was made by ArcGIS (http://www.arcgis.com/index.html\#).

\subsection{Instruments and methods}

The H-TDMA system is custom-made and consisted of two tandem differential mobility analyzers $\left(\mathrm{DMA}_{1}\right.$ and $\left.\mathrm{DMA}_{2}\right)$, one water-based condensation particle counter (WCPC), and a set of humidity and temperature control devices. Before getting into the instrument, the sampled aerosols first entered the Nafion dryer, reducing the RH to below $20 \%$. Then, the dried air flow went through a bipolar neutralizer to equilibrate the charge of the particles, after which the quasi-monodisperse particles $\left(\mathrm{D}_{0}\right.$, $40,80,110,150$, and $200 \mathrm{~nm}$ ) were selected by the $\mathrm{DMA}_{1}$. The particles entered to the $\mathrm{DMA}_{2}$ through 
which its size increased due to higher $\mathrm{RH}\left(\mathrm{D}_{\mathrm{p}}\right)$. The humidified tube between $\mathrm{DMA}_{1}$ and $\mathrm{DMA}_{2}$ is controlled at RH of $90 \%$. The hygroscopic growth factor (GF) of particles can be expressed as:

$130 \quad G F=\frac{D_{p}}{D_{0}}$

Before the measurement, the GF at different RHs was determined with pure ammonium sulfate to ensure the accuracy of the H-TDMA measurement (Badger et al., 2006). A full description of the principle, operation, and calibration of the instrument can be found in Tan et al. (2013).

We used the TDMA ${ }_{\text {inv }}$ algorithm (Gysel et al., 2009) to retrieve the actual GF probability density

135 function (GF-PDF) from the GF measured distribution function (GF-MDF). Petters and Kreidenweis et al. (2007) introduced the hygroscopicity parameter $\kappa$ into the $\kappa$-Köhler equation to characterize the hygroscopicity and activation capacity of aerosols, which is related to the GF and RH as follows:

$$
\kappa=\left(G F^{3}-1\right)\left[\frac{1}{R H} \exp \left(\frac{4 \sigma M_{w}}{R T \rho_{w} D_{0} G F}\right)-1\right]
$$

Where, $\mathrm{RH}$ is the relative humidity ( $90 \%$ in this study), $\sigma$ is the surface tension of the solution/air interface (here assumed to be the surface tension of pure water interface, about $0.0728 \mathrm{~N} \mathrm{~m}^{-2}$ ), $M_{\mathrm{w}}$ is the molecular weight of water $\left(\mathrm{kg} \mathrm{mol}^{-1}\right), R$ is the universal gas constant, $T$ is the temperature $(\mathrm{K}), \rho_{\mathrm{w}}$ is the density of water $\left(\mathrm{kg} \mathrm{m}^{-3}\right)$, and $D_{0}$ is the dry particle size of aerosols $(\mathrm{m})$. The observed GF value was substituted into Equ. (2) to obtain the hygroscopic parameter $\kappa$.

The retrieved GF-PDF (c $\left(G F, D_{d}\right)$ ) was normalized to unity in this study. The ensemble mean GF of GF-PDF (Sjogren et al., 2008), namely the number-weighted mean GF (GF mean), is defined as below:

$$
G F_{\text {mean }}=\int_{0}^{\infty} G F c\left(G F, D_{d}\right) d G F
$$

The corresponding ensemble mean $\kappa$ can be derived from mean GF by using Equ. (2). Because of the complex source, chemical composition and mixing state of ambient aerosols, different hygroscopic modes always appear in different field measurements. To better understand the hygroscopicity and mixing state of size-resolved particles, we divided them into nearly hydrophobic mode $(\mathrm{NH}, \mathrm{GF} \leq 1.21)$, less hygroscopic mode $(\mathrm{LH}, 1.21<\mathrm{GF} \leq 1.37)$, and more hygroscopic mode $(\mathrm{MH}, \mathrm{GF}>1.37)$ (Liu et al., 2011). For each mode, the number fraction (NF) can be determined from the GF-PDF as follows: 
$\mathrm{NF}=\int_{\text {start }}^{\text {end }} c\left(G F, D_{d}\right) d \kappa$

Apart from H-TDMA, the non-refractory chemical compositions in $\mathrm{PM}_{2.5}$ were measured simultaneously using a quadrupole aerosol chemical speciation monitor (Q-ACSM) in real time (Peck et al., 2016), the black carbon (BC) mass concentrations were measured using an aethalometer (AE-33, Magee Scientific) (Zhao et al., 2017). The time resolution of both Q-ACSM and AE-33 was 1 minute. The particle number size distributions (PNSDs) of environmental aerosols $(10-600 \mathrm{~nm})$ were measured by a scanning mobility particle sizer (SMPS, TSI) with a time resolution of 5 minute (Collins et al., 2002).

\section{Results and discussion}

\subsection{Measured time series of GF-PDFs}

Figure 2 shows the time series of GF-PDFs of the 40- and 150-nm particles at the five sampling sites. The white space in the Fig. 2 denotes missing values or outliers caused by the instrument malfunction. In general, large variations of the GF-PDFs were observed at all the sites, showing significant temporal changes in the properties of hygroscopic growth of the fine aerosol particles. For 40-nm particles, apparent bimodal shape of strong and weak hygroscopic modes in GF-PDFs, with GF of $\sim 1.5$ and $\sim 1.1$ respectively, were observed at the three mega-city sites (GZ, SH and BJ), while only strong hygroscopic mode (with GF of 1.5 and 1.8) dominated the GF-PDFs at the two more rural sites (XZ and XT). This indicates different mixing states of ambient aerosol particles between urban and non-urban regions on account of their contrasting emission sources. Owing to the continued local primary emissions in the populated regions, the freshly emitted hydrophobic ultrafine particles do not immediately mix with the background aerosol particles. As a result, the bimodal distributions of both hydrophilic and hydrophobic modes were present in GF-PDFs at the three urban sites, while the aerosol particles at the two non-urban sites are much less impacted by the local sources and more aged and internally mixed, and thus being more hygroscopic.

Previous observations have also shown that the XZ site is relatively clean (Zhang et al., 2017) and has uniform aerosol chemical compositions (Wang et al., 2016). For 150-nm particles, the hygroscopic 
mode in the GF-PDF is basically more dominant at all the five sites, suggesting that the aerosol particles $\mathrm{nm}$ particles was occasionally present in the time series of GF-PDF at the BJ site, due to the abundant traffic emissions and cooking sources near the site. In addition, the hydrophilic mode of 150-nm particles has generally larger GF values than that of $40-\mathrm{nm}$ particles, indicating a dependence of the particle hygroscopicity on particle size, which will be further discussed in Sect. 3.6.
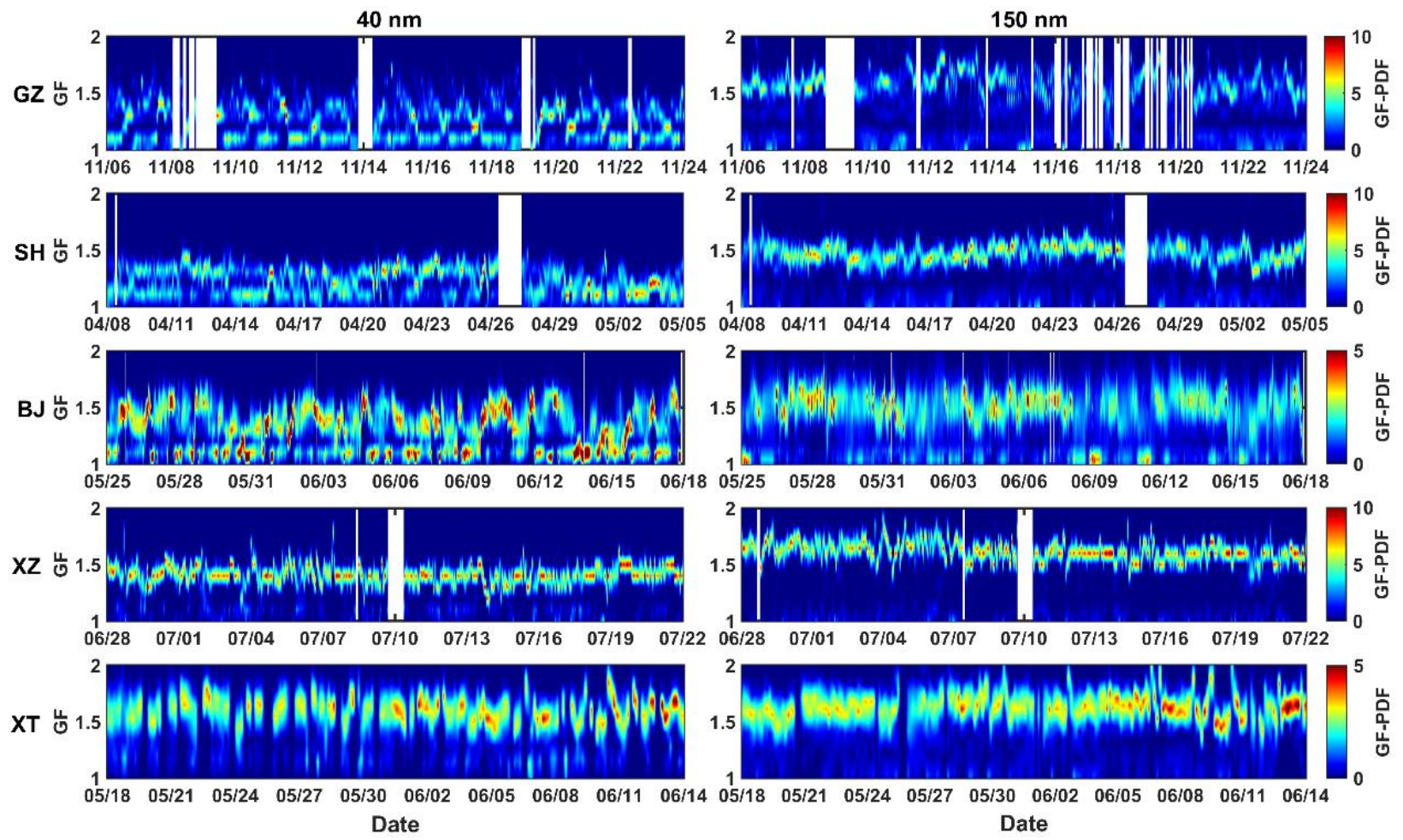

Figure 2. The time series of the probability density functions of growth factor (GF-PDFs) for 40- and 150-nm particles at different sampling sites (GZ, SH, BJ, XZ and XT site). The colour scales denote the GF-PDF.

The campaign mean GF-PDF distributions present the hygroscopic growth properties of all measured particle diameters more clearly (Fig. 3). There were evident hydrophobic modes, particularly

190 for 40-nm and 80-nm particles, at the urban sites which are affected greatly by primary emissions (traffic, cooking, etc.) (Tan et al., 2013). At the non-urban sites, however, the hydrophobic modes of GF-PDFs were negligible throughout the whole measured sizes. The hydrophilic modes at the XZ site for each measured particle sizes were narrower and more concentrated, reflecting the uniformity of the particle compositions. 


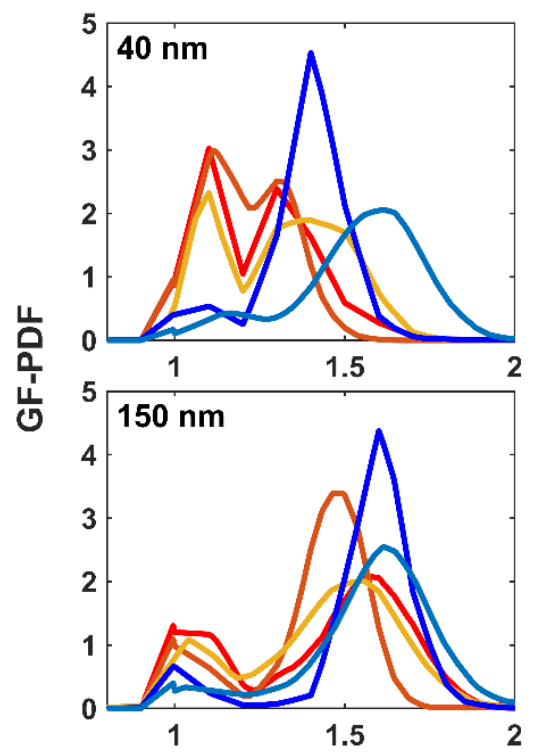

195

Figure 3. Mean probability density functions of growth factor (GF-PDFs) for different particle sizes (40-200 $\mathrm{nm}$ ) derived from H-TDMA data at different sampling sites.

\subsection{Diurnal variations of GF-PDFs}

Figure 4 shows the diurnal variations of size-resolved GF-PDFs at these sites. In general, the diurnal variations of GF-PDFs varied largely from site to site for 40-nm and 80-nm particles. At these megacities where the atmosphere was heavily impacted by local primary emissions, the diurnal patterns of GF-PDFs of the small particles exhibited bimodal distributions in both hydrophobic and hydrophilic modes. The proportion of the hydrophilic modes showed an increase around noontime (at the GZ and SH site) or early afternoon (at the BJ site), with a corresponding decrease or even disappearance of the hydrophobic modes. This could be associated with the nucleation process in the daytime, which was demonstrated that the growth of the newly formed particles is mainly contributed by hydrophilic matters (e.g., sulfate and organic acids) (Yue et al., 2010; Wu et al., 2013; Liu et al., 2021). By contrast, there is only hydrophilic mode for different sizes of the fine particles and no evident diurnal variations at the suburb site of XZ. At the XT site, the GF value of particles with different sizes in the daytime was higher than that at nighttime, but the diurnal patterns become less evident with the increase of particle size, indicating that the larger particles are more homogenously composed compared to the small ones. Overall, at the urban sites, the mean GF for 110-, 150- and 200-nm particles was basically higher in the 
daytime than nighttime, indicating photochemical aging processes in the daytime enhanced the particles hygroscopicity (Wu et al., 2015; Liu et al., 2021). In addition, due to the lift of planetary boundary layer (PBL) height after the sunrise, the aging particles above PBL could be mixed to that below PBL (Zhang et al., 2016), making the particles at all the sites more dominated by the strong hygroscopic mode.
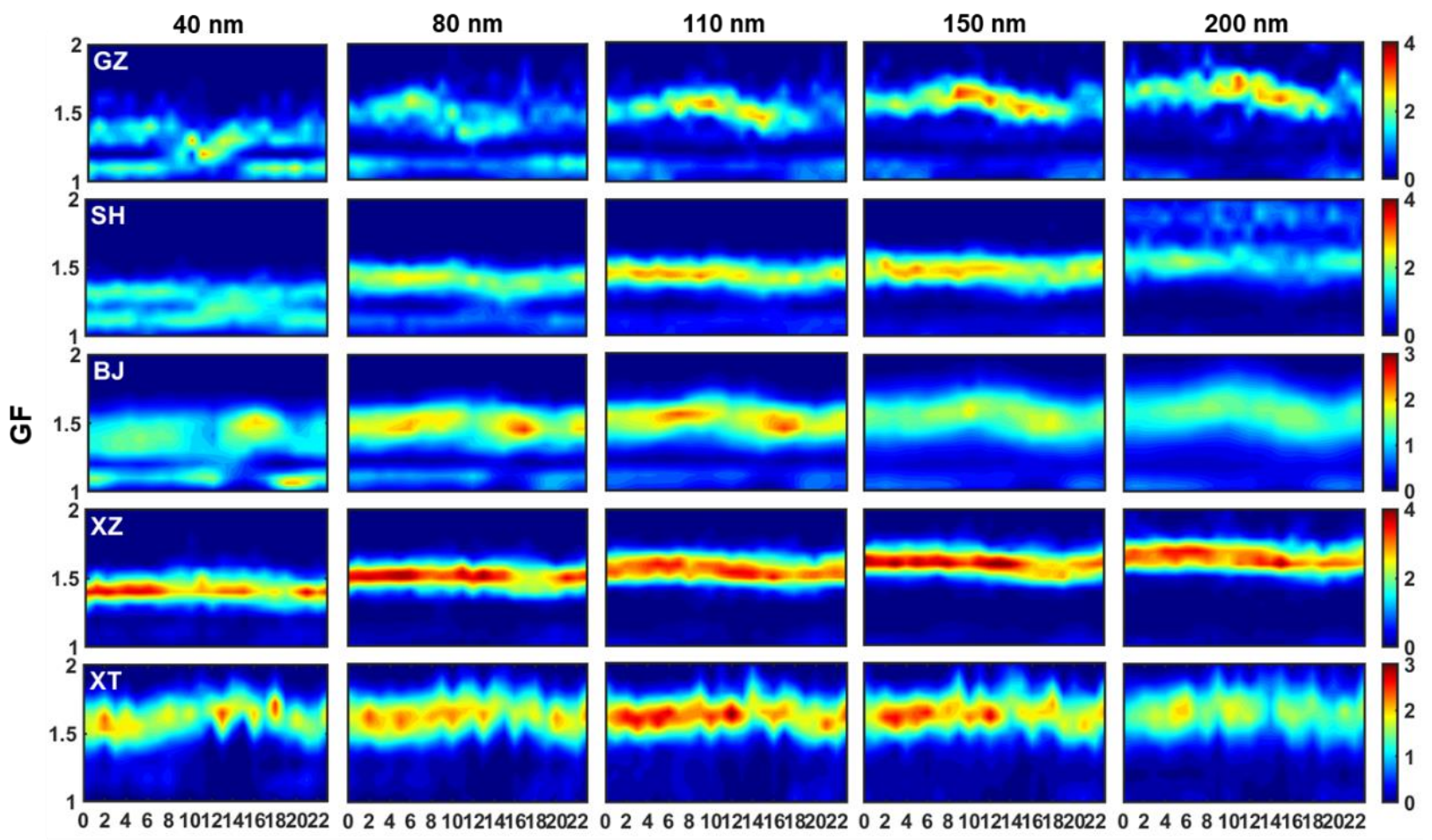

Local hour

Figure 4. Campaign-averaged diurnal variations of GF-PDFs for all measured dry particle sizes (40-200 nm) at different sampling sites (GZ, SH, BJ, XZ and XT site). The colour scales denote the GF-PDF.

\subsection{Number fraction of hydrophobic, less hygroscopic, and more hygroscopic mode of the fine aerosol particles}

To better understand the hygroscopicity and mixing state of size-resolved particles at the five sites, we divided the observed GF-PDFs into three modes, nearly hydrophobic mode, less hygroscopic mode, and more hygroscopic mode (Liu et al., 2011; Wang et al., 2017). The NH mode particles in submicron

225 aerosols are mainly composed of externally-mixed primary BC, primarily emitted organic matter and their mixtures, while MH mode particles primarily consist of internally-mixed hygroscopic secondary organic and inorganic matter, or their mixtures with primary emissions. So, the different modes 
represent different aerosol composition and formation pathway. Figure 5 gives the comparison of the campaign mean number fractions of the NH, LH and MH for 40-, 80-, 110-, 150- and 200-nm particles at the five sites. Obviously, at the suburb $\mathrm{XZ}$ and $\mathrm{XT}$ sites, the $\mathrm{MH}$ modes were typically more abundant than other sites for 40 -nm particles, with number fractions larger than $80 \%$, corresponding to the NH modes of only $\sim 10 \%$. At the urban sites of GZ, SH and BJ, however, $\mathrm{NH}$ mode accounted larger fractions of $\sim 40 \%$, and the values decreased with the increase of particle size. As a result, the $\mathrm{MH}$ modes for 40-nm particles at the urban sites only accounted for a number fraction of $20-40 \%$. The results are basically comparable with those reported in other field campaigns in urban (e.g. Meier et al., 2009; Tan et al., 2013; Enroth et al., 2018) and suburb (e.g. Liu et al., 2011; Zhang et al., 2016; Tao et al., 2020) regions. The MH mode generally dominates at relative remote sites where the atmosphere is less impacted by local primary sources, whereas the hydrophobic mode accounts for higher fraction at those urban sites.

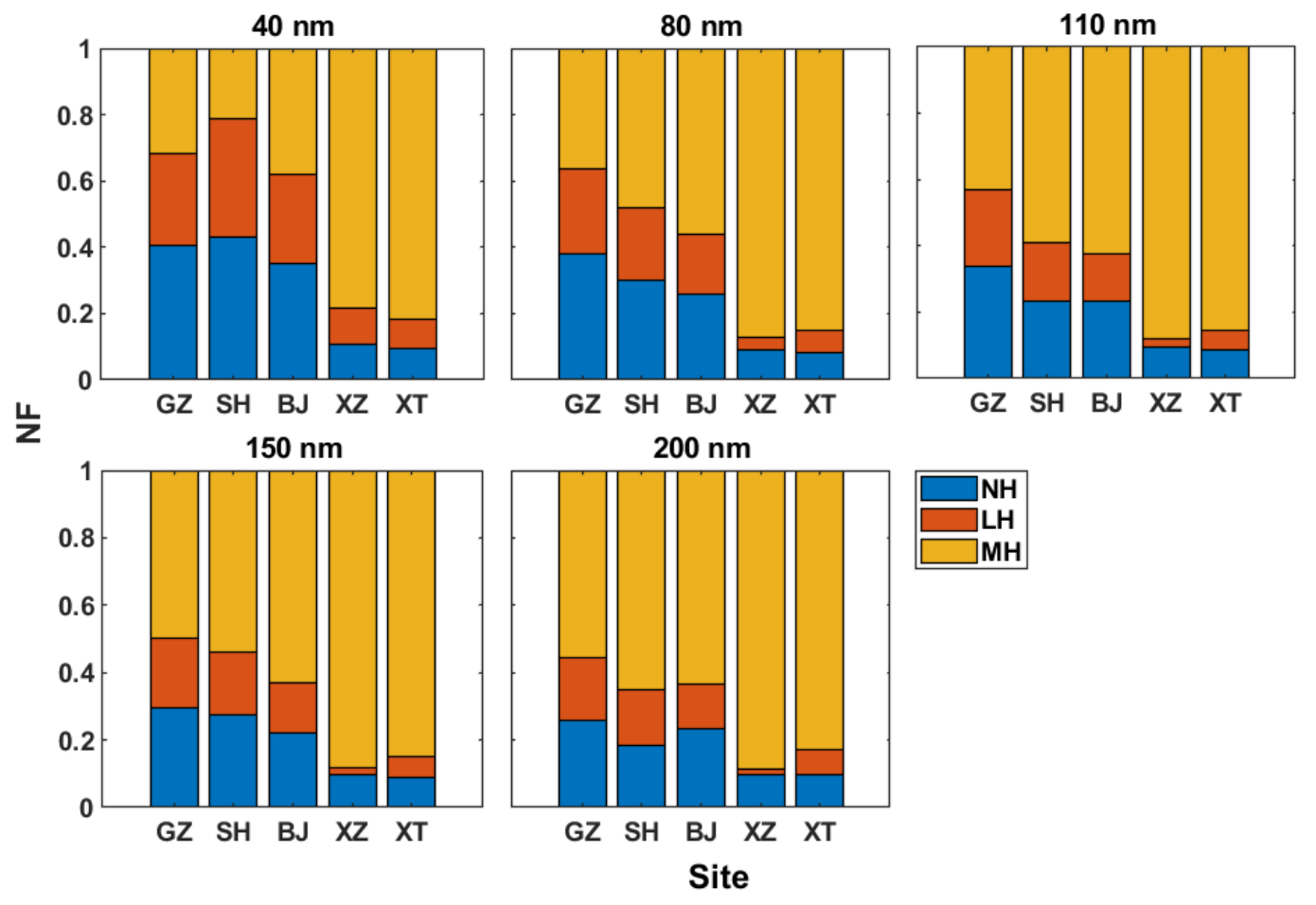

Figure 5. Campaign-averaged number fraction (NF) of nearly hydrophobic ( $\mathrm{NH}$, blue), less hygroscopic ( $\mathrm{LH}$, orange), and more hygroscopic (MH, yellow) group for 40- and 110- and 200-nm particles at each site. 


\subsection{Dependence of the particle hygroscopic properties on mass concentrations of $\mathbf{P M}_{2.5}$}

Given that the relationship between aerosol hygroscopicity and pollution levels is still unclear and varies greatly from regions to regions. Here, we examined and compared the dependence of the number fraction of the $\mathrm{NH}$ and $\mathrm{MH}$ mode and mean GF on $\mathrm{PM}_{2.5}$ mass concentrations at the five sites (Fig. 6 and Fig. 7). It shows that, there is no obvious dependence of number fraction of $\mathrm{NH}$ and $\mathrm{MH}$ mode on the $\mathrm{PM}_{2.5}$ mass concentration for 40-nm particles at all the five sites, which could be expected due to the low mass fraction of ultrafine particles. In other words, this means that, whether in urban or suburban sites, the proportion of $\mathrm{MH}$ and $\mathrm{NH}$ modes of the ultrafine particles is not subject to changes of the pollution conditions. However, for accumulated particles of about 100-200 nm particles, with the increase of $\mathrm{PM}_{2.5}$ mass concentration, the fraction of $\mathrm{MH}$ mode roughly increased towards 1 , and the fraction of $\mathrm{NH}$ mode reduced to nearly 0 at the $\mathrm{BJ}, \mathrm{XZ}$ and $\mathrm{XT}$ sites, indicating that the more particles are hygroscopic during the pollution episodes. On the contrary, the number fraction of MH mode declined slightly for $40-150 \mathrm{~nm}$ particles with the increase of $\mathrm{PM}_{2.5}$ mass concentration at the GZ site. No obvious trend was observed at $\mathrm{SH}$ for it is clean overall with $\mathrm{PM}_{2.5}$ mass concentration less than 60 $\mu \mathrm{g} \mathrm{m}^{-3}$ during the campaign.

Figure 7 shows that, with the increase of $\mathrm{PM}_{2.5}$ mass concentration, there was insignificant variations in $\mathrm{GF}_{\text {mean }}$ for 40-nm particles. The particles became more hygroscopic with the increase of $260 \mathrm{PM}_{2.5}$ mass concentration at $\mathrm{BJ}, \mathrm{XZ}$ and $\mathrm{XT}$. But at GZ, the aerosol particles were less hygroscopic generally with decreased $\mathrm{GF}_{\text {mean }}$ values under higher $\mathrm{PM}_{2.5}$. The distinct changes of aerosol particles hygroscopic behavior with variations of $\mathrm{PM}_{2.5}$ concentration among different sites suggest differences in particle composition and mixing state with the evolution of pollution events in different regions of China. The results also point to different formation mechanisms or aerosol sources regulating and 265 driving the air pollution in these regions. 
(a)
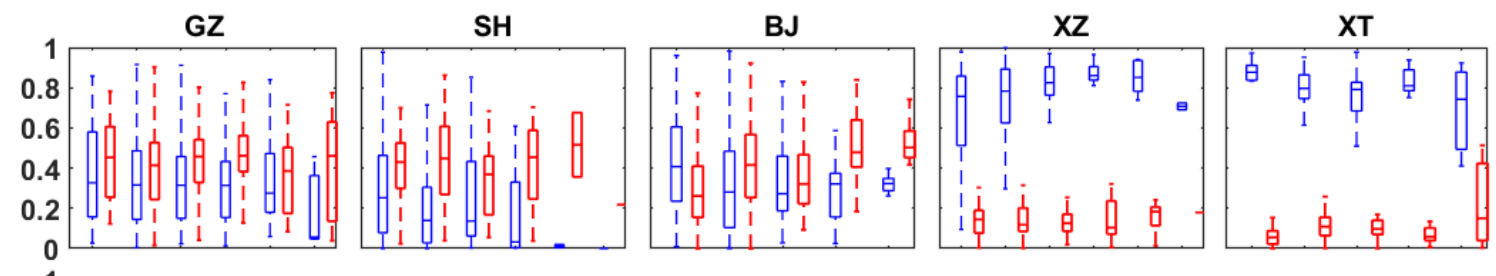

(b)
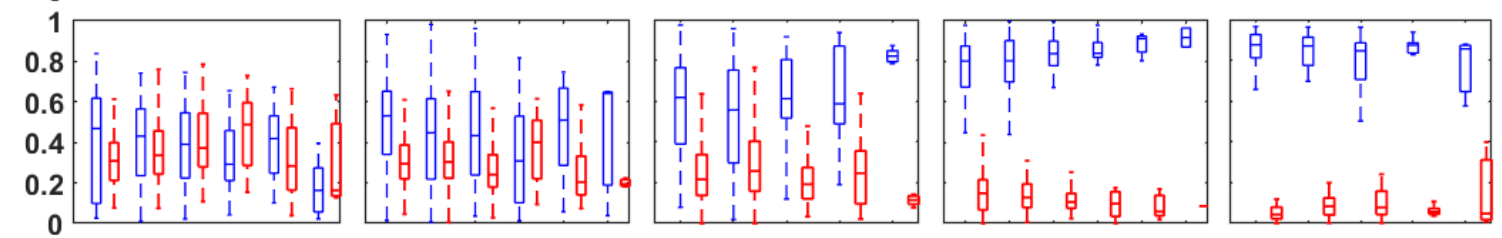

(c)
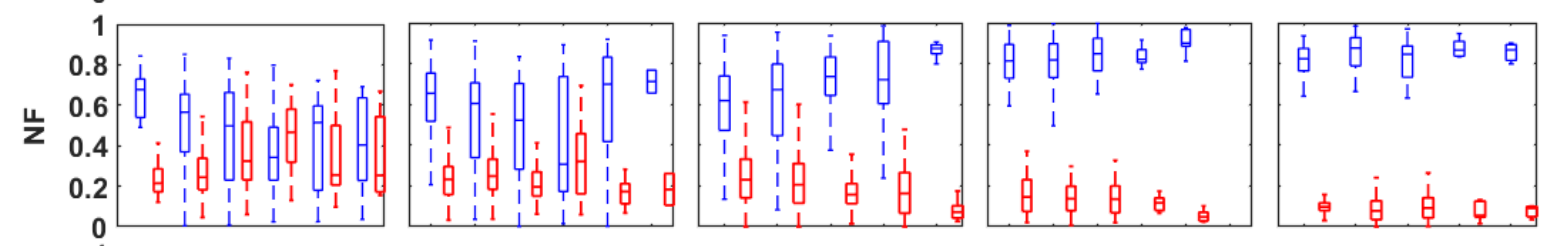

(d)
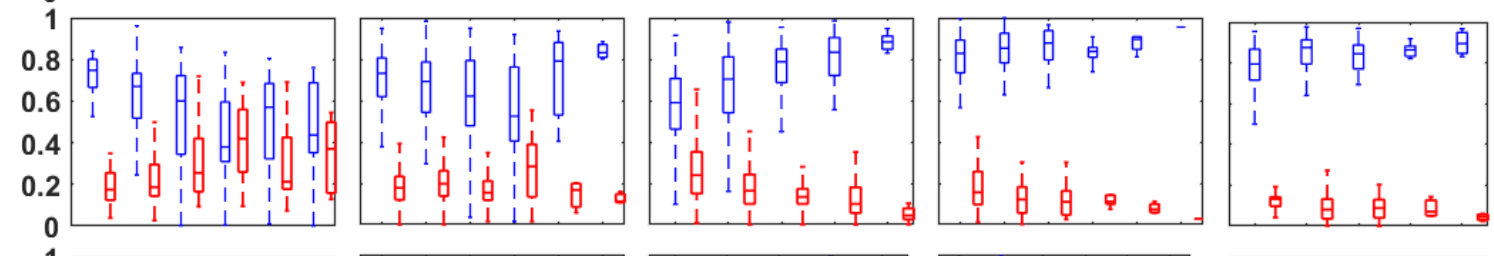

(e)
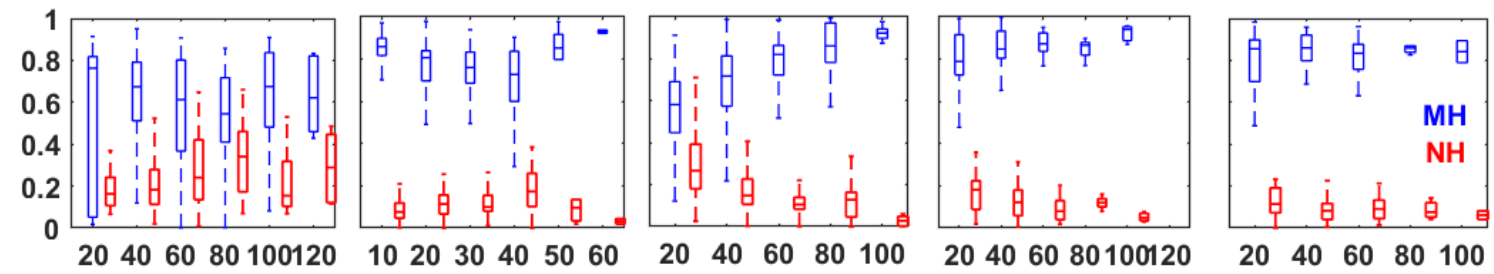

$\mathrm{PM}_{2.5}$ mass conc. $\left(\mu \mathrm{g} \mathrm{m}^{-3}\right)$

Figure 6. Box diagram for the number fraction of nearly hydrophobic $(\mathrm{NH})$ mode (red) and more hygroscopic (MH) mode (blue) of (a-e) all selected diameter particles $(40-200 \mathrm{~nm})$ under different $\mathrm{PM}_{2.5}$ mass concentration from all sampling sites. The horizontal line in the block diagram represents the median, the upper and lower borders represent the 25 th and 75 th percentiles, and the upper and lower borders of the dotted vertical line represent the 10th and 90th percentiles. 

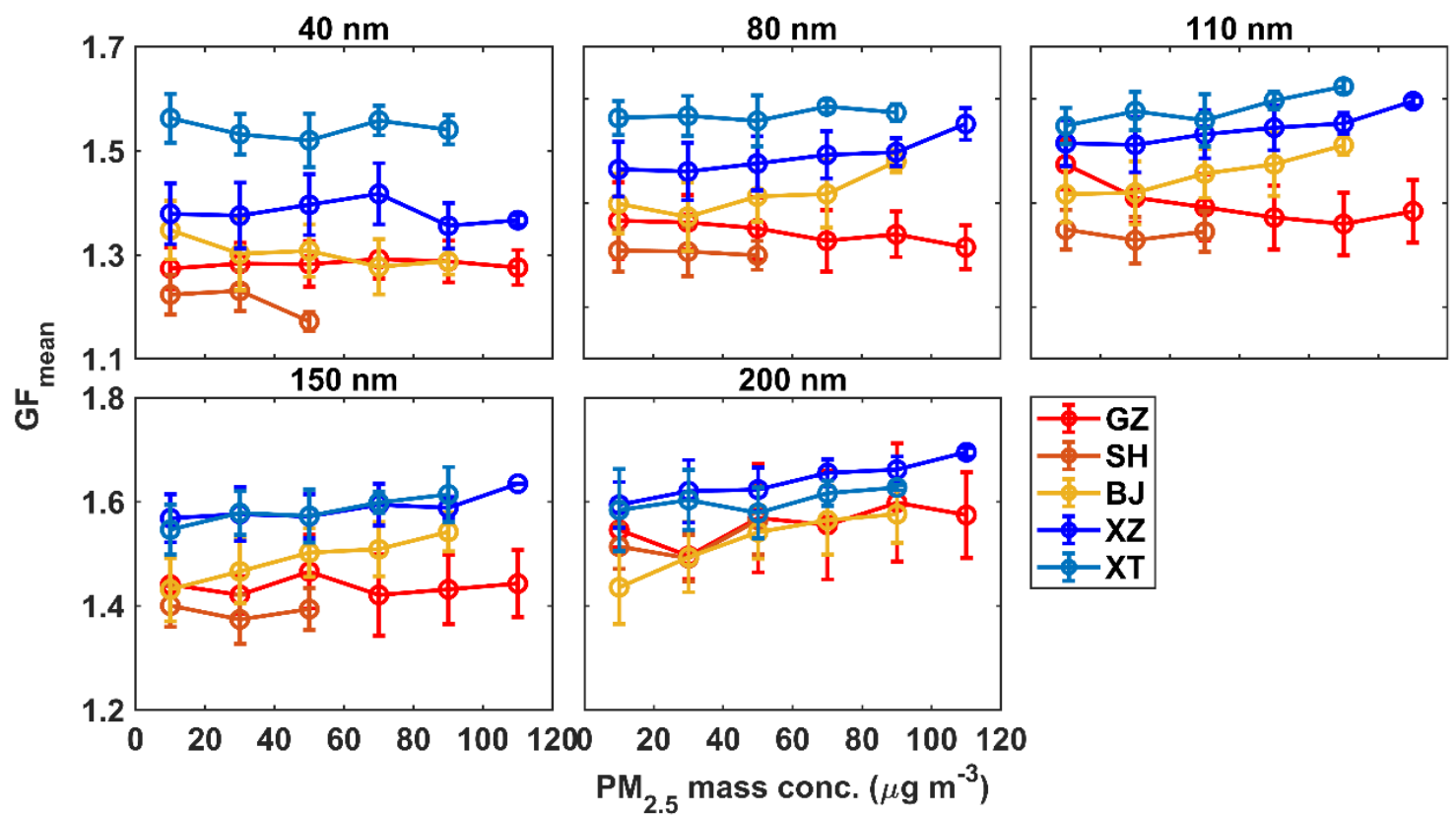

Figure 7. The mean value of number-weighted mean growth factor $\left(\mathrm{GF}_{\text {mean }}\right)$ of all selected diameter particles (40$200 \mathrm{~nm}$ ) under different $\mathrm{PM}_{2.5}$ mass concentrations from all sampling sites.

\subsection{Measured GF-PDFs of ultrafine particles during NPF and non-NPF events}

In order to understand the effects of NPF on particle hygroscopic behavior, we examined the GFPDFs of ultrafine particles during the evolutions of NPF and non-NPF events. Fig. 8 displays the mean diurnal variations of PNSDs and GF-PDFs for 40-nm particles on the NPF and non-NPF days. A typical NPF event is usually with a "banana" shape that can be observed on the PNSDs, showing a sudden appearance and continuous growth of ultrafine particles (Dal et al., 2005; Wu et al., 2015). The particle size of $40 \mathrm{~nm}$, which can represent the NPF-tracked particles, was thus selected. In this study, 4, 4, 8, 7 and $8 \mathrm{NPF}$ events at the GZ, SH, BJ, XZ and XT sites occurred respectively and were selected for a further study. NPF events started at around 09:00 LT (Fig. 8a) at nearly all sites. After the onset of NPF,

285 the hygroscopic modes in GF-PDFs at the sites of BJ, XZ and XT were obviously enhanced, corresponding to significant increases in the $\mathrm{GF}_{\text {mean }}$ values (Fig. 8b). This suggests that the more hygroscopic chemical components were formed in the nucleation and growth processes, leading to an increase in the number fraction of hydrophilic mode. Liu et al., (2021) showed an obvious enhanced hygroscopicity of 40-nm organic aerosol (OA) particles during NPF events in urban Beijing, and Shantz 
et al. (2012) and Wu et al. (2016) also observed an enhancement of the fraction of water-soluble compounds in the newly formed particles, showing that more than $40 \%$ of 50 -nm newly formed particles are water-soluble compounds. In addition, the sulfuric acid may be a dominated contributor to new particle growth in NCP (Yue et al., 2010). While at the GZ site, the GF mean increased very slightly; at the $\mathrm{SH}$ site, it is even declined from the beginning to the end of the NPF event, showing that the NPF processes generated less hygroscopic particles. The decreased GF of the nucleated particles would also relate to the chemical component participating in the nucleating and growth processes. It is likely that those hydrophobic secondary organic aerosols (SOA) (with GF of 1.1 at 90\% RH) (Kulmala et al., 2013) may play an important role in the growth process of the newly formed particles at GZ and SH sites. This result is also consistent with the previous study performed in clean environments, the newly formed particles consisted of a minor fraction of water-soluble fraction, and the GF value of the newly formed particles decreased with the particle growing (Wu et al., 2013; Kawana et al., 2017; Li et al., 2017). Compared to NPF days, no significant elevations on non-NPF days were observed in $\mathrm{GF}_{\text {mean }}$ in daytime at all the sites (Figs. 8d and 8e), further demonstrating the effect of NPF on the particles hygroscopicity. The distinct changes of aerosol particles hygroscopic behavior at the sites indicate that different compositions of the nucleated particles in different regions of China, which further reflects different formation mechanisms regulating the new particle formation in diverse atmospheric environment.

Also, the GF mean of the 40-nm particles on NPF days is generally greater than particles with the same sizes during non-NPF days (Fig. 9), further confirming the role of nucleation process on enhancing the particle hygroscopicity. For accumulated particles, the $\mathrm{GF}_{\text {mean }}$ values during non-NPF days are overall higher than that on NPF days at the BJ, XZ and XT site, due to that the larger particles are probably from secondary conversion and primarily composed by more hygroscopic substances on non-NPF days. But, at the GZ and SH sites, the $\mathrm{GF}_{\text {mean }}$ values for larger particles are lower during nonNPF days, suggesting primary sources of the accumulated particles at the two sites. 
(a)

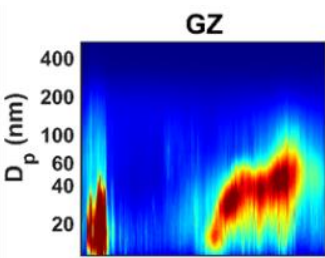

(b)

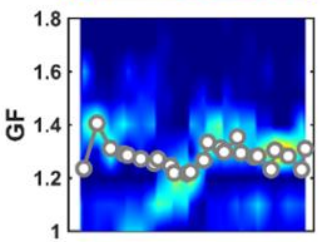

(c)

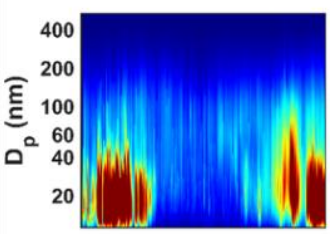

(d)

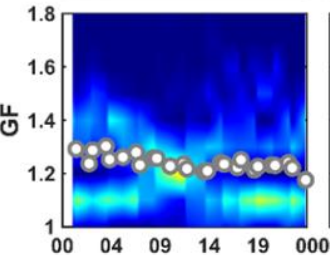

SH
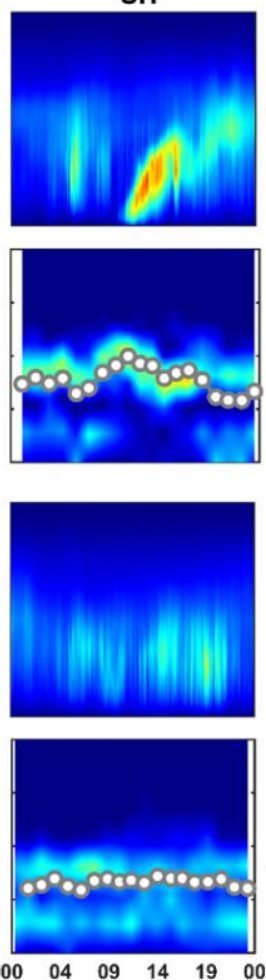

BJ
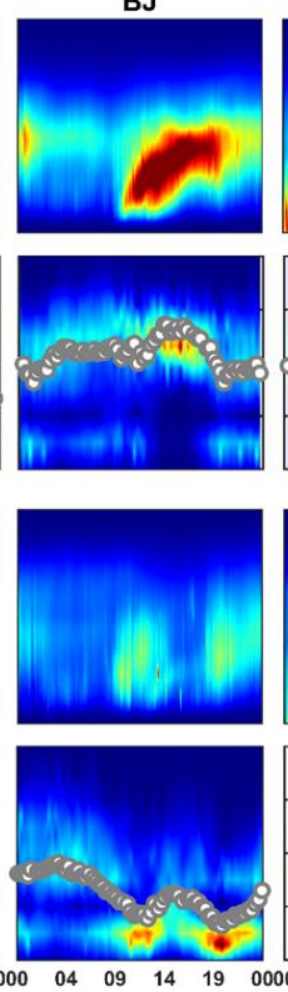

Local hour
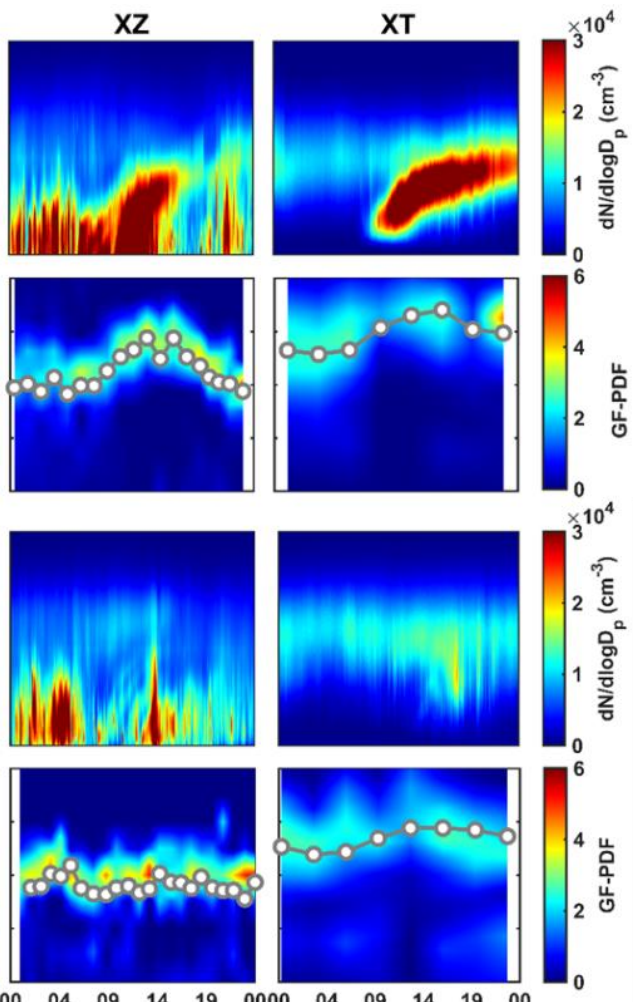

Figure 8. The mean variation in particle number size distributions (PNSDs), and the probability distribution functions of growth factor (GF-PDFs) for 40-nm particles during (a-b) NPF and (c-d) non-NPF days at the five sampling sites.
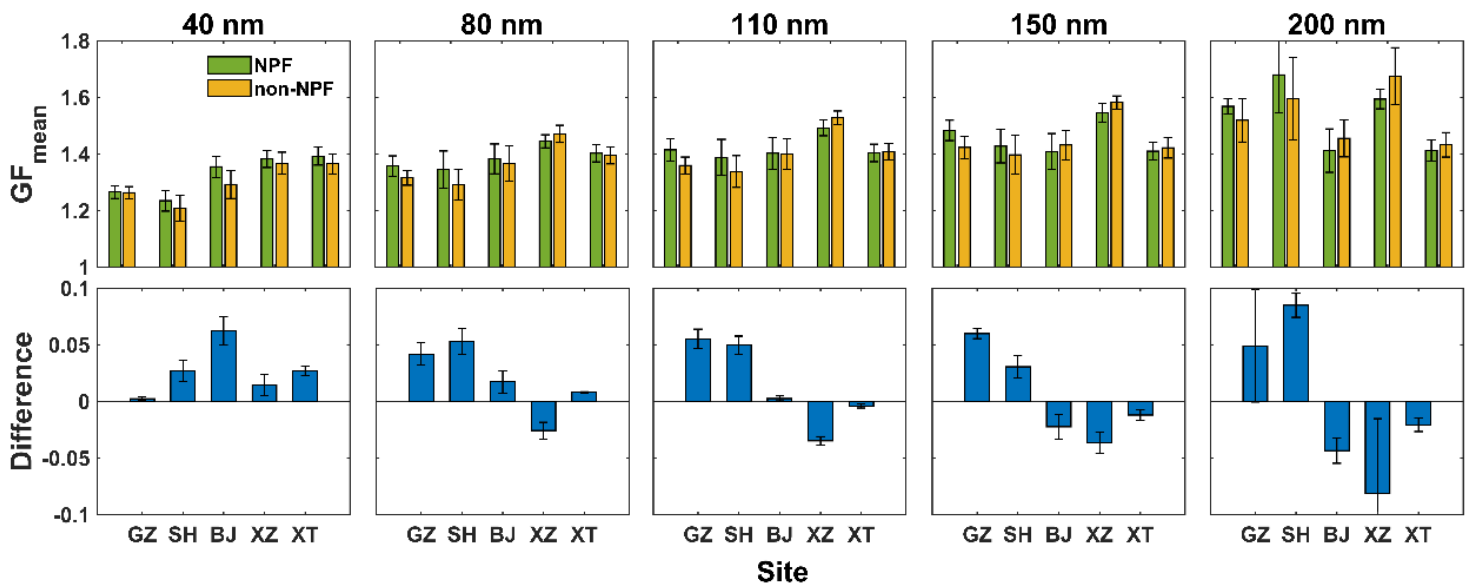

320 Figure 9. The mean values and differences of number-weighted mean growth factor $\left(\mathrm{GF}_{\text {mean }}\right)$ during NPF and non-NPF days for particles with the size of 40-200 $\mathrm{nm}$ from all sampling sites. The difference represents the $\mathrm{GF}_{\text {mean }}$ of NPF days minus the $\mathrm{GF}_{\text {mean }}$ of non-NPF days. 


\subsection{Size-resolved hygroscopic parameter $(\kappa)$ of fine aerosol particles}

To further investigate the relationship between the aerosol hygroscopicity and the chemical composition in different regions of China, we presented campaign mean size-resolved $\kappa$ calculated from the H-TDMA measurements (Fig. 10a) and the measured bulk mass concentrations fraction of chemical components in $\mathrm{PM}_{2.5}$ measured by the ACSM (Fig. 10b). Clearly, it shows that the aerosol hygroscopicity was closely relevant to the chemical compositions. That is, the aerosol particles were found more hygroscopic with larger $\kappa$ values at the sites such as $\mathrm{BJ}, \mathrm{XZ}$ and $\mathrm{XT}$ where the inorganics account for a large mass fraction in $\mathrm{PM}_{2.5}$; while they were less hygroscopic when the organics dominated the chemical composition at the sites of GZ and SH. Previously, a quite weak hygroscopicity of organic materials (with $\mathrm{GF}_{\text {org }}$ ranging between 1 and 1.1) has been observed at GZ (Hong et al., 2018). Whereas, the greater $\kappa$ values at BJ were not only caused by the high mass fraction of hygroscopic inorganic salts (e.g. sulfate, nitrate) in $\mathrm{PM}_{2.5}$, but also because the organics were demonstrated more hygroscopic with mean $\kappa$ values of $\sim 0.28$ in urban Beijing (Liu et al., 2021). Fig. 10c shows a comparison of size-dependent $\kappa$ values reported in previous studies and that observed in this study. Generally, the mean $\kappa$ values of the particles at all measured sizes are greater in suburban regions (Zhang et al., 2016; Wang et al., 2017) compared to those of measured in megacities (Tan et al., 2013; Ye et al., 2013; Xu et al., 2015; Jiang et al., 2016; Wu et al., 2016). This is consistent with that observed at the five sites by this study. However, it exhibits a wide and large variability of $\kappa$ values among different sites at a given $\mathrm{D}_{\mathrm{p}}$. The large spatial difference in $\kappa$ values suggests the different emission sources and the complex atmospheric physical and chemical processes, which could be significantly different under diverse ambient conditions. This is particularly true for the particles with small size. Note that the $\kappa$ values observed at the five sites are more consistent for 200-nm particles,

345 which is owing to that the larger particles are normally more aged and with homogenous compositions (Wang et al., 2018). 
(a)

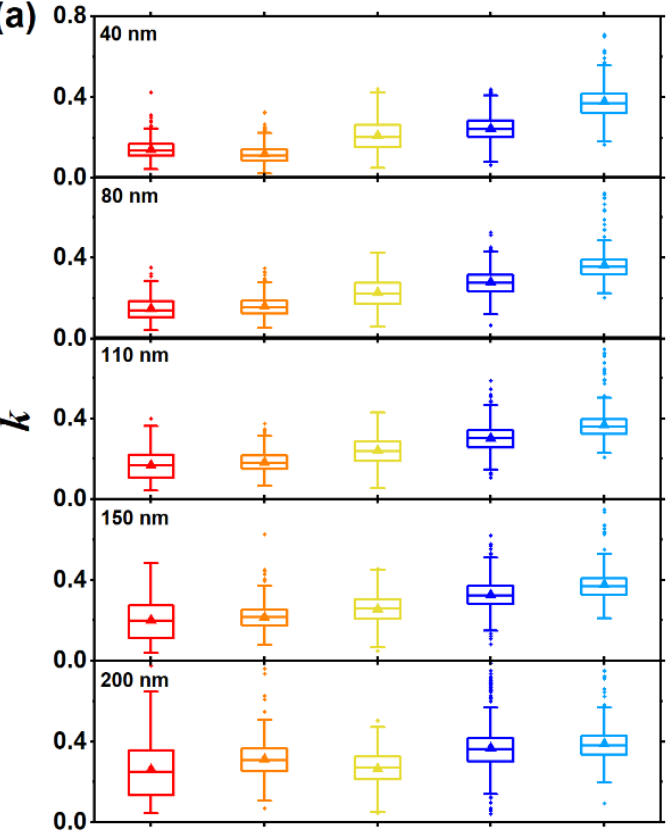

(b)

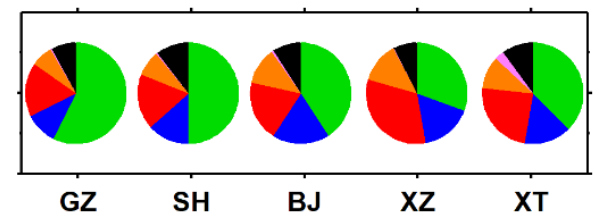

(c)
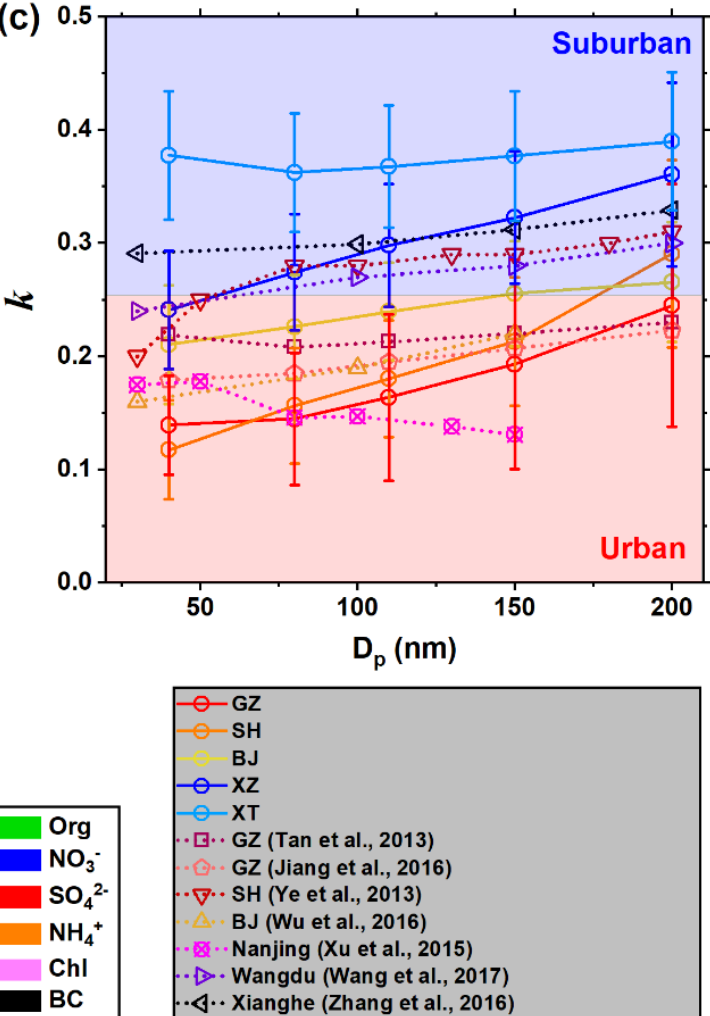

Figure 10. (a) Size-resolved hygroscopicity parameters $(\kappa)$ for all measured particle sizes at different sites. The figure shows the mean $\kappa$ (solid triangle markers) with boxes showing the 25th, 50th, and 75 th percentiles. The solid points represent outliers. (b) Campaign-averaged bulk mass fraction of chemical compositions of $\mathrm{PM}_{2.5}$. The BC mass concentration of the GZ site is based on the data measured in January 2020 due to the lack of observations in November 2019. (c) size-dependent $\kappa$ for all measured particle sizes retrieved from the H-TDMA measurements at different sites and reported by previous studies (Tan et al., 2013; Jiang et al., 2016; Ye et al., 2013; Wu et al., 2016; Xu et al., 2015; Wang et al., 2017; Zhang et al., 2016). The error bars represent $\pm 1 \sigma$.

\section{Conclusion}

In this study, the hygroscopic growth factors at five sites including three urban and two non-urban sites across China were investigated to understand its characteristics and the impact of mixing states of aerosols under diverse environmental conditions. The study made use of comprehensive measurements of size-resolved particles $(40-200 \mathrm{~nm})$ at RH of $90 \%$ made with a H-TDMA system, combined with the chemical composition and particle number size distribution measured by a ACSM and a SMPS respectively. There exist hydrophobic modes of GF-PDFs at the GZ, SH and BJ site for small particles, 
the unimodal hydrophilic modes throughout the whole measured sizes dominant at the $\mathrm{XZ}$ and $\mathrm{XT}$ sites. The more hygroscopic mode (MH) mode was typically more abundant at the $\mathrm{XZ}$ and XT site, with a corresponding number fractions of $>80 \%$, indicating that the particles at suburban sites were highly aged and internally mixed. The number fractions of MH modes account for only 20-40\% at those urban sites of GZ, SH and BJ. The diurnal patterns of GF-PDF at the megacity sites of GZ, SH and BJ show obvious enhancementent of the proportion of hydrophilic modes in daytime, however, such patterns are absent at the suburb sites of XZ and XT. Further analysis reveals that the aggravated $\mathrm{PM}_{2.5}$ pollution leads to more hygroscopic particles at the sites in north China (BJ, XZ and XT), but that is not the case in the southern sites (GZ and $\mathrm{SH}$ ). The distinct dependence of aerosol hygroscopicity on $\mathrm{PM}_{2.5}$ concentrations among the sites suggests the spatial variability of particle formation mechanisms with the evolution of pollution events in different regions of China. Moreover, the particle hygroscopicity during NPF and non-NPF days at each site was also investigated. The distinct particles hygroscopic behaviors during NPF events are observed at the five sites, demonstrating the different mechanisms of

$375 \mathrm{NPF}$ in diverse atmospheric environment. There was no obvious variation in particle hygroscopicity observed during non-NPF days at all the five sites.

Overall, the aerosol particles observed at the suburban sites are more hygroscopic than those of in megacities, but note that a wide and large variability in the hygroscopic parameter $\kappa$ among different sites at a given particle size suggests the complex impact from emission sources and atmospheric physical and chemical processes. Future field measurements and observations should be conducted at more sites with longer duration, so as to improve understanding of the formation of fine particles and the impact on regional environment and climate change.

Data availability. All data needed to evaluate the conclusions in the paper are present in the paper. Also, 385 all data used in the study are available from the corresponding author upon request (fang.zhang@bnu.edu.cn).

Author contributions. F. Z., L. C. and Z. L. conceived the conceptual development of the manuscript. L. C. directed and performed of the experiments with D. Z., J. L., S. J., and J. R., and L. C. conducted the 
data analysis and wrote the draft of the manuscript, and all authors edited and commented on the

Declaration of competing interest. The authors declare no competing interests.

Acknowledgments. This work was funded by the National Basic Research Program of China (2017YFC1501702), the NSFC research projects (41975174, 41675141), and BNU Interdisciplinary Research Foundation for the First-Year Doctoral Candidates (Grant BNUXKJC2126). We thank all participants in the field campaigns for their tireless work and cooperation.

\section{References}

Badger, C. L., George, I., Griffiths, P. T., Braban, C. F., Cox, R. A. and Abbatt, J. P. D.: Phase transitions and hygroscopic growth of aerosol particles containing humic acid and mixtures of humic acid and ammonium sulphate, Atmos. Chem. Phys., 6(3), 755-768, doi:10.5194/acp-6-755-2006, $400 \quad 2006$.

Broday, D. M. and Georgopoulos, P. G.: Growth and Deposition of Hygroscopic Particulate Matter in the Human Lungs, Aerosol Sci. Technol., 34(1), 144-159, doi:10.1080/02786820118725, 2001.

Cai, M., Tan, H., Chan, C. K., Mochida, M., Hatakeyama, S., Kondo, Y., Schurman, M. I., Xu, H., Li, F., Shimada, K., Li, L., Deng, Y., Yai, H., Matsuki, A., Qin, Y. and Zhao, J.: Comparison of aerosol

405 hygroscopcity, volatility, and chemical composition between a suburban site in the Pearl River Delta region and a marine site in Okinawa, Aerosol Air Qual. Res., 17(12), 3194-3208, doi:10.4209/aaqr.2017.01.0020, 2017.

Cai, M., Tan, H., Chan, C. K., Qin, Y., Xu, H., Li, F., Schurman, M. I., Liu, L. and Zhao, J.: The sizeresolved cloud condensation nuclei $(\mathrm{CCN})$ activity and its prediction based on aerosol hygroscopicity and composition in the Pearl Delta River (PRD) region during wintertime 2014, Atmos. Chem. Phys, 18, 16419-16437, doi:10.5194/acp-18-16419-2018, 2018.

Collins, D. R., Flagan, R. C., and Seinfeld, J. H.: Improved inversion of scanning DMA data, Aerosol Sci. Tech., 36, 1-9, 2002. 
Dal Maso, M., Kulmala, M., Riipinen, I., Wagner, R., Hussein, T., Aalto, P. P., and Lehtinen, K. E. J.: Formation and growth of fresh atmospheric aerosols: eight years of aerosol size distribution data from SMEAR II, Hyytiälä, Finland, Boreal Environ. Res., 10, 323-336, 2005.

Deng, Z. Z., Zhao, C. S., Ma, N., Ran, L., Zhou, G. Q., Lu, D. R., and Zhou, X. J.: An examination of parameterizations for the $\mathrm{CCN}$ number concentration based on in situ measurements of aerosol activation properties in the North China Plain, Atmos. Chem. Phys., 13, 6227-6237, 10.5194/acp-136227-2013, 2013.

Ehn, M., Petäjä, T., Aufmhoff, H., Aalto, P., Hämeri, K., Arnold, F., Laaksonen, A., and Kulmala, M.: Hygroscopic properties of ultrafine aerosol particles in the boreal forest: diurnal variation, solubility and the influence of sulfuric acid, Atmos. Chem. Phys., 7, 211-222, 10.5194/acp-7-211-2007, 2007.

Enroth, J., Mikkilä, J., Németh, Z., Kulmala, M., and Salma, I.: Wintertime hygroscopicity and volatility of ambient urban aerosol particles, Atmos. Chem. Phys., 18, 4533-4548, 10.5194/acp-184533-2018, 2018.

Fan, X., Liu, J., Zhang, F., Chen, L., Collins, D., Xu, W., Jin, X., Ren, J., Wang, Y., Wu, H., Li, S., Sun, Y. and Li, Z.: Contrasting size-resolved hygroscopicity of fine particles derived by HTDMA and HRToF-AMS measurements between summer and winter in Beijing: The impacts of aerosol aging and local emissions, Atmos. Chem. Phys., 20(2), 915-929, doi:10.5194/acp-20-915-2020, 2020.

Gasparini, R., Li, R. and Collins, D. R.: Integration of size distributions and size-resolved hygroscopicity measured during the Houston Supersite for compositional categorization of the aerosol, Atmos. Environ., 38(20), 3285-3303, doi:10.1016/j.atmosenv.2004.03.019, 2004.

Guo, S., Hu, M., Lin, Y., Gomez-Hernandez, M., Zamora, M. L., Peng, J., Collins, D. R. and Zhang, R.: OH-Initiated Oxidation of m-Xylene on Black Carbon Aging, Environ. Sci. Technol., 50(16), 86058612, doi:10.1021/acs.est.6b01272, 2016.

Gysel, M., McFiggans, G. B. and Coe, H.: Inversion of tandem differential mobility analyser (TDMA) measurements, J. Aerosol Sci., 40(2), 134-151, doi:10.1016/j.jaerosci.2008.07.013, 2009.

Hong, J., Xu, H., Tan, H., Yin, C., Hao, L., Li, F., Cai, M., Deng, X., Wang, N., Su, H., Cheng, Y., Wang, L., Petäjä, T. and Kerminen, V. M.: Mixing state and particle hygroscopicity of organic- 
dominated aerosols over the Pearl River Delta region in China, Atmos. Chem. Phys., 18(19), 1407914094, doi:10.5194/acp-18-14079-2018, 2018.

Huang, R.-J., Zhang, Y., Bozzetti, C., Ho, K.-F., Cao, J.-J., Han, Y., Daellenbach, K. R., Slowik, J. G., Platt, S. M., Canonaco, F., Zotter, P., Wolf, R., Pieber, S. M., Bruns, E. A., Crippa, M., Ciarelli, G., Piazzalunga, A., Schwikowski, M., Abbaszade, G., Schnelle-Kreis, J., Zimmermann, R., An, Z., Szidat, S., Baltensperger, U., Haddad, I. El and Prévôt, A. S. H.: High secondary aerosol contribution to particulate pollution during haze events in China, Nature, 514(7521), 218-222, doi:10.1038/nature13774, 2014.

Jiang, R., Tan, H., Tang, L., Cai, M., Yin, Y., Li, F., Liu, L., Xu, H., Chan, P. W., Deng, X. and Wu, D.: Comparison of aerosol hygroscopicity and mixing state between winter and summer seasons in Pearl River Delta region, China, Atmos. Res., 169, 160-170, doi:10.1016/j.atmosres.2015.09.031, 2016.

Jimenez, J. L., Canagaratna, M. R., Donahue, N. M., Prevot, A. S. H., Zhang, Q., Kroll, J. H., DeCarlo, P. F., Allan, J. D., Coe, H., Ng, N. L., Aiken, A. C., Docherty, K. S., Ulbrich, I. M., Grieshop, A. P., Robinson, A. L., Duplissy, J., Smith, J. D., Wilson, K. R., Lanz, V. A., Hueglin, C., Sun, Y. L., Tian, J., Laaksonen, A., Raatikainen, T., Rautiainen, J., Vaattovaara, P., Ehn, M., Kulmala, M., Tomlinson, J. M., Collins, D. R., Cubison, M. J., Dunlea, E. J., Huffman, J. A., Onasch, T. B., Alfarra, M. R., Williams, P. I., Bower, K., Kondo, Y., Schneider, J., Drewnick, F., Borrmann, S., Weimer, S., Demerjian, K., Salcedo, D., Cottrell, L., Griffin, R., Takami, A., Miyoshi, T., Hatakeyama, S., Shimono, A., Sun, J. Y., Zhang, Y. M., Dzepina, K., Kimmel, J. R., Sueper, D., Jayne, J. T., Herndon, S. C., Trimborn, A. M., Williams, L. R., Wood, E. C., Middlebrook, A. M., Kolb, C. E., Baltensperger, U. and Worsnop, D. R.: Evolution of organic aerosols in the atmosphere, Science (80. )., 326(5959), 1525-1529, doi:10.1126/science.1180353, 2009.

Kandler, K. and Schütz, L.: Climatology of the average water-soluble volume fraction of atmospheric aerosol, Atmos. Res., 83(1), 77-92, doi:10.1016/j.atmosres.2006.03.004, 2007.

465 Kreidenweis, S. M. and Asa-Awuku, A.: Aerosol Hygroscopicity: Particle Water Content and Its Role in Atmospheric Processes, in Treatise on Geochemistry: Second Edition, vol. 5, pp. 331-361, Elsevier Inc., 2013. 
Krüger, M., Mertes, S., Klimach, T., Cheng, Y., Su, H., Schneider, J., Andreae, M., Pöschl, U. and Rose, D.: Assessment of cloud supersaturation by aerosol particle and cloud condensation nuclei (CCN) measurements, Atmos. Meas. Tech. Discuss., 6, 10021-10056, doi:10.5194/amtd-6-10021-2013, 2013.

Levin, E. J. T., Prenni, A. J., Petters, M. D., Kreidenweis, S. M., Sullivan, R. C., Atwood, S. A., Ortega, J., DeMott, P. J., and Smith, J. N.: An annual cycle of size-resolved aerosol hygroscopicity at a forested site in Colorado, J. Geophys. Res., 117, D06201, 10.1029/2011jd016854, 2012.

Liu, J., Zhang, F., Xu, W., Sun, Y., Chen, L., Li, S., Ren, J., Hu, B., Wu, H., and Zhang, R.: Hygroscopicity of Organic Aerosols Linked to Formation Mechanisms, 48, e2020GL091683, https://doi.org/10.1029/2020GL091683, 2021.

Liu, P. F., Zhao, C. S., Göbel, T., Hallbauer, E., Nowak, A., Ran, L., Xu, W. Y., Deng, Z. Z., Ma, N., Mildenberger, K., Henning, S., Stratmann, F., and Wiedensohler, A.: Hygroscopic properties of aerosol particles at high relative humidity and their diurnal variations in the North China Plain, Atmos. Chem. Phys., 11, 3479-3494, 10.5194/acp-11-3479-2011, 2011.

Li, W., Sun, J., Xu, L., Shi, Z., Riemer, N., Sun, Y., Fu, P., Zhang, J., Lin, Y., Wang, X., Shao, L., Chen, J., Zhang, X., Wang, Z. and Wang, W.: A conceptual framework for mixing structures in individual aerosol particles, J. Geophys. Res. Atmos., 121(22), 13,713-784,798, doi:https://doi.org/10.1002/2016JD025252, 2016.

Li, Y., Zhang, F., Li, Z., Sun, L., Wang, Z., Li, P., Sun, Y., Ren, J., Wang, Y., Cribb, M. and Yuan, C.: Influences of aerosol physiochemical properties and new particle formation on CCN activity from observation at a suburban site of China, Atmos. Res., 188, 80-89, doi:https://doi.org/10.1016/j.atmosres.2017.01.009, 2017.

Liu, P. F., Zhao, C. S., Göbel, T., Hallbauer, E., Nowak, A., Ran, L., Xu, W. Y., Deng, Z. Z., Ma, N., Mildenberger, K., Henning, S., Stratmann, F. and Wiedensohler, A.: Hygroscopic properties of aerosol particles at high relative humidity and their diurnal variations in the north China plain, Atmos. Chem. Phys., 11(7), 3479-3494, doi:10.5194/acp-11-3479-2011, 2011.

Li, Z., Wang, Y., Guo, J., Zhao, C., Cribb, M. C., Dong, X., Fan, J., Gong, D., Huang, J., Jiang, M., 495 Jiang, Y., Lee, S. S., Li, H., Li, J., Liu, J., Qian, Y., Rosenfeld, D., Shan, S., Sun, Y., Wang, H., Xin, 
J., Yan, X., Yang, X., Yang, X.-q., Zhang, F., and Zheng, Y.: East Asian Study of Tropospheric Aerosols and their Impact on Regional Clouds, Precipitation, and Climate (EAST-AIRCPC), Journal of Geophysical Research: Atmospheres, 124, 13026-13054, https://doi.org/10.1029/2019JD030758, 2019.

Massling, A., Stock, M., Wehner, B., Wu, Z. J., Hu, M., Brüggemann, E., Gnauk, T., Herrmann, H. and Wiedensohler, A.: Size segregated water uptake of the urban submicrometer aerosol in Beijing, Atmos. Environ., 43(8), 1578-1589, doi:10.1016/j.atmosenv.2008.06.003, 2009.

McMurry, P. H., Litchy, M., Huang, P.-F., Cai, X., Turpin, B. J., Dick, W. D. and Hanson, A.: Elemental composition and morphology of individual particles separated by size and hygroscopicity with the TDMA, Atmos. Environ., 30(1), 101-108, doi:https://doi.org/10.1016/1352-2310(95)00235Q, 1996.

Meier, J., Wehner, B., Massling, A., Birmili, W., Nowak, A., Gnauk, T., Brüggemann, E., Herrmann, H., Min, H. and Wiedensohler, A.: Hygroscopic growth of urban aerosol particles in Beijing (China) during wintertime: a comparison of three experimental methods, Atmos. Chem. Phys., 9(18), 68656880, doi:10.5194/acp-9-6865-2009, 2009.

Müller, A., Miyazaki, Y., Aggarwal, S. G., Kitamori, Y., Boreddy, S. K. R. and Kawamura, K.: Effects of chemical composition and mixing state on size-resolved hygroscopicity and cloud condensation nuclei activity of submicron aerosols at a suburban site in northern Japan in summer, J. Geophys. Res. Atmos., 122(17), 9301-9318, doi:10.1002/2017JD027286, 2017.

515 Peck, J., Gonzalez, L. A., Williams, L. R., Xu, W., Croteau, P. L., Timko, M. T., Jayne, J. T., Worsnop, D. R., Miake-Lye, R. C., and Smith, K. A.: Development of an aerosol mass spectrometer lens system for PM2.5, Aerosol Sci. Tech., 50, 781-789, https://doi.org/10.1080/02786826.2016.1190444, 2016.

Peters, A., Wichmann, H. E., Tuch, T. and Heyder, J.: Respiratory effects are associated with the number of ultrafine particles, Am. J. Respir. Crit. Care Med., 155, 1376-1383, doi:10.1164/ajrccm.155.4.9105082, 1997. 
Pitchford, M. L. and McMurry, P. H.: Relationship between measured water vapor growth and chemistry of atmospheric aerosol for Grand Canyon, Arizona, in winter 1990, Atmos. Environ., 28(5), 827-839, doi:https://doi.org/10.1016/1352-2310(94)90242-9, 1994.

Sakurai, H., Fink, M. A., McMurry, P. H., Mauldin, L., Moore, K. F., Smith, J. N., and Eisele, F. L.: Hygroscopicity and volatility of 4-10 $\mathrm{nm}$ particles during summertime atmospheric nucleation events in urban Atlanta, Journal of Geophysical Research: Atmospheres, 110, n/a-n/a, 10.1029/2005JD005918, 2005.

Shantz, N. C., Pierce, J. R., Chang, R. Y. W., Vlasenko, A., Riipinen, I., Sjostedt, S., Slowik, J. G.,

Wiebe, A., Liggio, J., Abbatt, J. P. D., and Leaitch, W. R.: Cloud condensation nuclei droplet growth kinetics of ultrafine particles during anthropogenic nucleation events, Atmospheric Environment, 47, 389-398, http://dx.doi.org/10.1016/j.atmosenv.2011.10.049, 2012.

Sun, Y. L., Wang, Z. F., Du, W., Zhang, Q., Wang, Q. Q., Fu, P. Q., Pan, X. L., Li, J., Jayne, J. and Worsnop, D. R.: Long-term real-time measurements of aerosol particle composition in Beijing, China: seasonal variations, meteorological effects, and source analysis, Atmos. Chem. Phys., 15(17), 1014910165, doi:10.5194/acp-15-10149-2015, 2015.

Sjogren, S., Gysel, M., Weingartner, E., Alfarra, M. R., Duplissy, J., Cozic, J., Crosier, J., Coe, H., and Baltensperger, U.: Hygroscopicity of the submicrometer aerosol at the high-alpine site Jungfraujoch, 3580 m a.s.1., Switzerland, Atmos. Chem. Phys., 8, 5715-5729, 10.5194/acp-8-5715-2008, 2008.

Swietlicki, E., Zhou, J., Berg, O. H., Martinsson, B. G., Frank, G., Cederfelt, S.-I., Dusek, U., Berner, A., Birmili, W., Wiedensohler, A., Yuskiewicz, B., and Bower, K. N.: A closure study of submicrometer aerosol particle hygroscopic behavior, Atmospheric Research, 50, 205-240, https://doi.org/10.1016/S0169-8095(98)00105-7, 1999.

Tan, H., Yin, Y., Gu, X., Li, F., Chan, P. W., Xu, H., Deng, X. and Wan, Q.: An observational study of the hygroscopic properties of aerosols over the Pearl River Delta region, Atmos. Environ., 77, 817826, doi:10.1016/j.atmosenv.2013.05.049, 2013.

Tan, H., Cai, M., Fan, Q., Liu, L., Li, F., Chan, P. W., Deng, X. and Wu, D.: An analysis of aerosol liquid water content and related impact factors in Pearl River Delta, Sci. Total Environ., 579, 18221830, doi:10.1016/j.scitotenv.2016.11.167, 2017. 
Tang, I. N. and Munkelwitz, H. R.: Water activities, densities, and refractive indices of aqueous sulfates and sodium nitrate droplets of atmospheric importance, J. Geophys. Res. Atmos., 99(D9), 1880118808, doi:https://doi.org/10.1029/94JD01345, 1994.

Tao, J., Kuang, Y., Ma, N., Zheng, Y., Wiedensohler, A., and Zhao, C.: An improved parameterization scheme for size-resolved particle activation ratio and its application on comparison study of particle hygroscopicity measurements between HTDMA and DMA-CCNC, Atmospheric Environment, 226, 117403, https://doi.org/10.1016/j.atmosenv.2020.117403, 2020.

Tritscher, T., Jurnyi, Z., Martin, M., Chirico, R., Gysel, M., Heringa, M. F., Decarlo, P. F., Sierau, B., Prévt, A. S. H., Weingartner, E. and Baltensperger, U.: Changes of hygroscopicity and morphology during ageing of diesel soot, Environ. Res. Lett., 6(3), 034026, doi:10.1088/1748-9326/6/3/034026, 5602011.

Vakkari, V., Tiitta, P., Jaars, K., Croteau, P., Beukes, J. P., Josipovic, M., Kerminen, V.-M., Kulmala, M., Venter, A. D., van Zyl, P. G., Worsnop, D. R., and Laakso, L.: Reevaluating the contribution of sulfuric acid and the origin of organic compounds in atmospheric nanoparticle growth, Geophysical Research Letters, 42, 10,486-410,493, https://doi.org/10.1002/2015GL066459, 2015.

Wang, Q., Zhao, J., Du, W., Ana, G., Wang, Z., Sun, L., Wang, Y., Zhang, F., Li, Z., Ye, X., and Sun, Y.: Characterization of submicron aerosols at a suburban site in central China, Atmospheric Environment, 131, 115-123, https://doi.org/10.1016/j.atmosenv.2016.01.054, 2016.

Wang, X., Shen, X. J., Sun, J. Y., Zhang, X. Y., Wang, Y. Q., Zhang, Y. M., Wang, P., Xia, C., Qi, X. F. and Zhong, J. T.: Size-resolved hygroscopic behavior of atmospheric aerosols during heavy aerosol pollution episodes in Beijing in December 2016, Atmos. Environ., 194, 188-197, doi:10.1016/j.atmosenv.2018.09.041, 2018a.

Wang, Y., Li, Z., Tan, H., Xu, H., Ren, J., Zhao, J., Du, W., Sun, Y. and Zhang, F.: Enhanced hydrophobicity and volatility of submicron aerosols under severe emission control conditions in Beijing, Atmos. Chem. Phys, 17, 5239-5251, doi:10.5194/acp-17-5239-2017, 2017.

575 Wang, Y., Li, Z., Zhang, Y., Du, W., Zhang, F., Tan, H., Xu, H., Jin, X., Fan, X., Dong, Z., Wang, Q. and Sun, Y.: Characterization of aerosol hygroscopicity, mixing state, and CCN activity at a suburban 
site in the central North China Plain, Atmos. Chem. Phys. Discuss., 1-34, doi:10.5194/acp-2017$1100,2018 b$.

Wang, Y., Li, Z., Zhang, R., Jin, X., Xu, W., Fan, X., Wu, H., Zhang, F., Sun, Y., Wang, Q., Cribb, M. and Hu, D.: Distinct Ultrafine- and Accumulation-Mode Particle Properties in Clean and Polluted Urban Environments, Geophys. Res. Lett., 46(19), 10918-10925, doi:10.1029/2019GL084047, 2019.

Weingartner, E., Gysel, M. and Baltensperger, U.: Hygroscopicity of Aerosol Particles at Low Temperatures. 1. New Low-Temperature H-TDMA Instrument: Setup and First Applications, Environ. Sci. Technol., 36(1), 55-62, doi:10.1021/es010054o, 2002.

Wu, Z. J., Poulain, L., Henning, S., Dieckmann, K., Birmili, W., Merkel, M., van Pinxteren, D., Spindler, G., Müller, K., Stratmann, F., Herrmann, H. and Wiedensohler, A.: Relating particle hygroscopicity and CCN activity to chemical composition during the HCCT-2010 field campaign, Atmos. Chem. Phys., 13(16), 7983-7996, doi:10.5194/acp-13-7983-2013, 2013.

Wu, Z. J., Zheng, J., Shang, D. J., Du, Z. F., Wu, Y. S., Zeng, L. M., Wiedensohler, A. and Hu, M.:

Particle hygroscopicity and its link to chemical composition in the urban atmosphere of Beijing, China during summertime, Atmos. Chem. Phys. Discuss., 15(8), 11495-11524, doi:10.5194/acpd-1511495-2015, 2015.

Xie, Y., Ye, X., Ma, Z., Tao, Y., Wang, R., Zhang, C., Yang, X., Chen, J., and Chen, H.: Insight into winter haze formation mechanisms based on aerosol hygroscopicity and effective density measurements, Atmos. Chem. Phys., 17, 7277-7290, https://doi.org/10.5194/acp-17-7277-2017, 2017.

Xu, B.; Zhang, Z.-f.; Li, Y.-w.; Qin, X.; Miao, Q.; Shen, Y., Hygroscopic Properties of Aerosol Particles in North Suburb of Nanjing in Spring (in Chinese). Huan jing ke xue= Huanjing kexue 2015, 36 (6), 1911-8.

Ye, X., Tang, C., Yin, Z., Chen, J., Ma, Z., Kong, L., Yang, X., Gao, W. and Geng, F.: Hygroscopic growth of urban aerosol particles during the 2009 Mirage-Shanghai Campaign, Atmos. Environ., 64, 263-269, doi:10.1016/j.atmosenv.2012.09.064, 2013.

Yue, D. L., Hu, M., Zhang, R. Y., Wang, Z. B., Zheng, J., Wu, Z. J., Wiedensohler, A., He, L. Y., Huang, X. F., and Zhu, T.: The roles of sulfuric acid in new particle formation and growth in the mega-city of Beijing, Atmos. Chem. Phys., 10, 4953-4960, 10.5194/acp-10-4953-2010, 2010. 
Zhang, J., Wang, L., Chen, J., Feng, S., Shen, J., and Jiao, L.: Hygroscopicity of ambient submicron particles in urban Hangzhou, China, Front. Environ. Sci. En., 5, 342-347, 2011.

Zhang, F., Wang, Y., Peng, J., Ren, J., Collins, D., Zhang, R., Sun, Y., Yang, X. and Li, Z.: Uncertainty in Predicting CCN Activity of Aged and Primary Aerosols, J. Geophys. Res. Atmos., 122(21), 11,723-11,736, doi:10.1002/2017JD027058, 2017.

Zhang, F., Ren, J., Fan, T., Chen, L., Xu, W., Sun, Y., Zhang, R., Liu, J., Jiang, S., Jin, X., Wu, H., Li, S., Cribb, M. C., and Li, Z.: Significantly Enhanced Aerosol CCN Activity and Number Concentrations by Nucleation-Initiated Haze Events: A Case Study in Urban Beijing, 124, 1410214113, https://doi.org/10.1029/2019JD031457, 2019.

Zhang, F., Wang, Y., Peng, J., Chen, L., Sun, Y., Duan, L., Ge, X., Li, Y., Zhao, J., Liu, C., Zhang, X., Zhang, G., Pan, Y., Wang, Y., Zhang, A. L., Ji, Y., Wang, G., Hu, M., Molina, M. J. and Zhang, R.: An unexpected catalyst dominates formation and radiative forcing of regional haze, Proc. Natl. Acad. Sci., 117(8), 3960 LP - 3966, doi:10.1073/pnas.1919343117, 2020.

Zhang, R., Khalizov, A. F., Pagels, J., Zhang, D., Xue, H. and McMurry, P. H.: Variability in morphology, hygroscopicity, and optical properties of soot aerosols during atmospheric processing, Proc. Natl. Acad. Sci., 105(30), 10291 LP - 10296, doi:10.1073/pnas.0804860105, 2008.

Zhang, S. L., Ma, N., Kecorius, S., Wang, P. C., Hu, M., Wang, Z. B., Größ, J., Wu, Z. J. and Wiedensohler, A.: Mixing state of atmospheric particles over the North China Plain, Atmos. Environ., 125, 152-164, doi:10.1016/j.atmosenv.2015.10.053, 2016.

Zhao, J., Du, W., Zhang, Y., Wang, Q., Chen, C., Xu, W., Han, T., Wang, Y., Fu, P., Wang, Z., Li, Z., and Sun, Y.: Insights into aerosol chemistry during the 2015 China Victory Day parade: results from simultaneous measurements at ground level and $260 \mathrm{~m}$ in Beijing, Atmos. Chem. Phys., 17, 32153232, https://doi.org/10.5194/acp-17-3215-2017, 2017. 